\title{
VIVÊNCIAS MATERNAS SOBRE A ASSISTÊNCIA RECEBIDA NO PROCESSO DE PARTURIÇÃO ${ }^{a}$
}

\author{
Vivencias maternas sobre asistencia recibida en el trabajo de parto \\ Maternal experiences on the assistance received in the process of parturition
}

Viviane Marten Milbrath ${ }^{1}$

Simone Coelho Amestoy²

Deisi Cardoso Soares ${ }^{3}$

Hedi Crecencia Heckler de Siqueira ${ }^{4}$

\section{RESUMO}

Esse estudo teve por objetivo conhecer as vivências maternas sobre a assistência recebida durante o trabalho de par to e parto em que o filho sofreu asfixia perinatal grave. Trata-se de uma pesquisa descritiva-exploratória com abordagem qualitativa. Os dados foram coletados por meio da entrevista semiestruturada, com seis mulheres que vivenciaram o processo de parturição em que seus filhos sofreram asfixia perinatal grave, no período de 2005-2007, na cidade de Rio Grande/RS. Os resultados apontaram aspectos positivos e negativos na assistência recebida durante o processo da parturição. Como positivos emergiram: o diálogo, a confiança e a agilidade no atendimento. Como aspectos negativos destacaram-se: o despreparo do profissional para assistir a mulher no momento da intercorrência durante o trabalho de par to e parto; a desumanização na assistência; e a ausência de um acompanhante durante o processo. Salienta-se a necessidade de se rever a assistência prestada à mulher durante o processo de parturição.

Palavras-chave: Asfixia Neonatal. Enfermagem. Parto. Saúde Materno-Infantil.

\begin{abstract}
This study aimed to know the maternal experiences on the assistance received during labor process and delivery in which his son suffered severe perinatal asphyxia. This is a descriptive and exploratory research with a qualitative approach. The data were collected through semi-structured interviews, with six women who experienced the process of parturition in which their sons suffered severe perinatal asphyxia, in the period of 2005-2007 in the city of Rio Grande / RS. The results showed positive and negative aspects of assistance received during the process of parturition. As positive results emerged the dialogue, confidence and agility in attendance. As negative aspects are highlighted the lack of professional prepared to assist the woman at the moment of complications during the labor process and delivery, the dehumanization of assistance, and the absence of a companion during the process. It emphasizes the need to review the assistance provided to women in the process of parturition.
\end{abstract}

Keywords: Asphyxia Neonatorum. Nursing. Parturition. Maternal and Child Health

\section{Resumen}

Este estudio tuvo como objetivo comprender las vivencias maternas sobre la asistencia recibida durante el trabajo de parto y parto en el que su hijo sufrió asfixia perinatal severa. Esta es una investigación exploratoria y descriptiva con un enfoque cualitativo. Los datos fueron recolectados a través de entrevistas semi-estructuradas con seis mujeres que experimentaron en el trabajo de parto en el que sus hijos sufrieron asfixia perinatal severa, en el período 2005-2007 en la ciudad de Rio Grande / RS. Los resultados mostraron aspectos positivos y negativos de la asistencia recibida durante el trabajo de parto. Surgió como resultados positivos: el diálogo, la confianza y agilidad en a asistencia. Como aspectos negativos se destacan: la falta de profesionales preparados para ayudar la mujer en el momento de las complicaciones durante el trabajo de parto y parto, la deshumanización de la asistencia, y ausencia de un acompañante durante el proceso. Es de extrema necesidad que se revise la asistencia prestada a las mujeres en el trabajo de parto.

Palabras-clave: Asfixia Neonatal. Enfermería. Parto. Salud Materno-Infantil

\footnotetext{
${ }^{1}$ Enfermeira Mestre em Enfermagem pela FURG. Doutoranda em Enfermagem pela UFRGS. Bolsista REUNI. Membro do Núcleo de Estudos e Pesquisa: Gerenciamento Ecossistêmico em Enfermagem/Saúde (GEES).Rio Grande-RS-Brasil. E-mail: vivimarten@ig.com.br, ${ }^{2}$ Enfermeira. Mestre em Enfermagem pela Universidade Federal do Rio Grande. Doutoranda em Enfermagem pela UFSC. Bolsista CNPq.Rio Grande-RS-Brasil. E-mail: samestoy@terra.com.br, ${ }^{3}$ Enfermeira. Mestre em Enfermagem pela Universidade Federal do Rio Grande. Membro do Núcleo de Pesquisa GEES. Professora da UFPel.Pelotas-RS-Brasil. E-mail: Deisy@bol.com.br, ${ }^{4}$ Enfermeira. Mestre e Doutora em Enfermagem. Especialista em Administração Hospitalar. Docente do Programa de Pós-Graduação em Enfermagem da FURG. Membro Líder do Núcleo de Pesquisa GEES.Pelotas-RS-Brasil. E-mail: hedihs@terra.com.br
} 


\section{INTRODUÇÃO}

A gravidez é considerada um fenômeno especialmente significativo na vida da mulher. É compreendido como um processo delicado, em que ocorrem modificações biológicas, emocionais, subjetivas e sociais, capazes de envolver não apenas a mulher, mas também seu companheiro e a teia de interrelações a qual pertencem. ${ }^{1,2}$ Ao longo dos três trimestres da gestação, a mulher tem aflorados sentimentos jamais vividos anteriormente e que são, muitas vezes, expressos de forma ambígua, como a capacidade que possuem de assustar e alegrar. ${ }^{1,3}$

À medida que a gestação evolui, a mulher apresenta alterações fisiológicas, emocionais e psicológicas que vão se exacerbando com a proximidade do parto. A chegada do nono mês traz várias modificações fisiológicas: o feto ganha peso e volume, aumentam as contrações, intensificam-se as ansiedades. ${ }^{2}$ À medida que o parto se aproxima gera na mulher o temor à morte, à dor, ao parto traumático. Surgem dúvidas e medos em relação ao bebê e vários questionamentos se apresentam: vai nascer antes, depois ou dentro do prazo previsto, será "normal" ou portará alguma deficiência, ou, ainda, vai viver ou morrer. ${ }^{2-4}$

As mães, em sua maioria, sabem que as condições de nascimento de uma criança têm uma representatividade no seu desenvolvimento posterior. Hoje não é tão raro os pais perguntarem ao neonatologista qual a nota que o recém-nato recebeu. ${ }^{5}$ Uma intercorrência, como no caso da asfixia perinatal grave, durante o parto aumenta os sentimentos de temor e ansiedade na parturiente. ${ }^{6}$

A gestação e o parto constituem uma das experiências humanas mais significativas e impactantes na vida da mulher., ${ }^{4,7}$ Essa vivência pode ser muito positiva e enriquecedora para a mulher, mas em contrapartida essa mesma vivência pode ser percebida por ela como um processo traumático, decorrente da ausência de cuidado durante esse momento, influenciando negativamente suas experiências futuras. ${ }^{\text {? }}$

A singularidade e a complexidade que permeiam 0 processo de parturição, seja ele "normal" ou com intercorrências clínicas, emana a necessidade de se ter um acompanhamento durante esse processo, permeado pela confiança e segurança entre o profissional de saúde e a mulher. ${ }^{7}$ Uma atenção de qualidade e humanizada é fundamental para a manutenção da saúde materna e neonatal. ${ }^{8}$

Humanizar a assistência prestada à mulher no processo de parturição é sinônimo de entender essa mulher e sua família em sua singularidade, com necessidades especificas, que extrapolam as questões biológicas e abrangem as circunstâncias sociais, éticas, educacionais e psíquicas presentes nos relacionamentos humanos. ${ }^{9}$

Cientes da importância do cuidado prestado à mulher durante 0 trabalho de parto, principalmente quando se têm intercorrências no processo, objetivou-se nesse trabalho conhecer as vivencias maternas sobre a assistência recebida durante o trabalho de parto e parto em que seu filho sofreu asfixia perinatal grave.

\section{MÉTODO}

Para a realização desse estudo, utilizou-se uma metodologia descritiva e exploratória à luz de uma abordagem qualitativa.

A escolha dos sujeitos foi realizada com a finalidade de contemplar todas as mães das crianças que nasceram com APGAR menor ou igual a 3 no quinto minuto com diagnóstico de asfixia perinatal grave, na cidade do Rio Grande (RS) nos anos de 2005, 2006 e 2007. A busca dos sujeitos foi realizada em duas etapas.

A primeira etapa foi caracterizada pela captação dos sujeitos, a qual se desprendeu de outro estudo das pesquisadoras, intitulado "Estudo da prevalência do nascimento de crianças portadoras de necessidades especiais" aprovado pelo Comitê de Ética em pesquisa da Associação de Caridade Santa Casa do Rio Grande sob o número 030/2007. Esse estudo permitiu estratificar todos os nascimentos na cidade do Rio Grande nos anos de 2005, 2006 e 2007, possibilitando realizar a busca de todas as crianças que nasceram com APGAR menor ou igual a 3 no quinto minuto, perfazendo um total de 32 recém-nascidos, dos quais sete sobreviveram. Vale ressaltar que as autoras optaram por abordar apenas as mulheres cujos filhos sobreviveram.

A segunda etapa da pesquisa envolveu a busca destas sete crianças. Entretanto, uma não foi encontrada, perfazendo um total de seis crianças. Sendo assim, o estudo possui um total de seis mulheres as quais foram identificadas por pseudônimos de Mãe1, Mãe2, até a Mãe6, respectivamente, conforme a ordem da entrevista.

0 projeto de pesquisa foi encaminhado e aprovado pelo Comitê de Ética em pesquisa da Associação de Caridade Santa Casa do Rio Grande, sob o número 002/2008. Os sujeitos foram contatados em suas residências e convidados a participarem do estudo. Ao expor a proposta, foi solicitado por escrito, conforme a Resolução n 196/96 do Conselho Nacional de Saúde, o Consentimento Livre e Esclarecido dos participantes, assinado em duas vias, ficando uma com 0 participante e outra com as pesquisadoras. Foram enfatizados os aspectos legais e éticos envolvidos e a liberdade de desistência em qualquer momento, se assim desejassem, sem nenhum prejuízo pessoal, bem como foram garantidos 0 anonimato e o sigilo.

Os dados foram coletados por meio de uma entrevista semiestruturada, cuja gravação foi permitida por todos os sujeitos. De posse dos dados, optou-se por analisá-los pela análise temática, que consiste em três etapas: pré-análise, 
exploração dos dados, tratamento dos resultados obtidos e interpretação. $^{10}$

\section{RESULTADOS E DISCUSSÃO}

Com a análise dos depoimentos dos atores sociais desse estudo encontraram-se aspectos positivos e negativos na assistência recebida durante o trabalho de parto e parto. Como aspectos positivos emergiram: o diálogo com a parturiente; a confiança no profissional que faria o procedimento; e a agilidade no atendimento. Como aspectos negativos destacaram-se: 0 despreparo do profissional para assistir a mulher no momento da intercorrência durante 0 trabalho de parto e parto; a desumanização na assistência; e a não presença de um acompanhante durante o processo.

\section{Aspectos positivos durante a assistência ao trabalho de parto e parto}

0 processo de parturição pode ser considerado um momento de grande impacto para a mulher/parturiente, principalmente quando, durante esse período, ocorrem intercorrências com o neonato, situação que "exige" dos profissionais que estão prestando assistência naquele momento uma conduta que consiga atender a parturiente em todos os seus aspectos, valorizando-a como um ser humano biopsicossocioespiritual. Nessa perspectiva, as mulheres, ao serem perguntadas a respeito da assistência recebida durante o trabalho de parto e parto apontaram alguns aspectos positivos em suas falas:

Meu parto foi um parto cesariano, e fui muito bem atendida; não tenho queixa nenhuma, fui bem tranquilizada, os médicos conversaram comigo, não tive problema nenhum, nem após a cesárea eu não tive nada (Mãe 1).

[...]pra ganhar também não tive nenhum problema, esperei e deu, e pra ganhar também foi muito rápido (Mãe 2).

Eu cheguei, e eles me disseram que era pra eu vir, em seguida chegou a minha doutora, a doutora (nome), e falou: "que está fazendo aí? Mexendo comigo. Aíme fizeram lá uns exames, e ela viu que tinha que fazer um parto cesárea de urgência, porque ela já tava passando, e ela já tava pronta pra fazer, foi tudo rápido, porque ela aspirou mecônio, aí que fizeram a cirurgia (Mãe 3).

Não fiquei internada, eu só fui a consulta naquele mesmo dia e, ele ligou para (nome do hospital) e disse que eu tava hipertensa e, que tinha que fazer uma cesárea naquela hora. A barriga estava murchando, tanto que ele viu os batimentos dele e depois eles não acharam, foibem rápido, passeinafrente das outras pessoas que estavam lá, foibem ligeira a cesárea (Mãe 6).

A Mãe 1, ao dizer "fui bem tranquilizada, os médicos conversaram comigo", demonstra sentimento de segurança pela forma como foi atendida. 0 apoio emocional e constante na hora do parto é característica de um parto humanizado, em que o processo de parturição é facilitado, pois a parturiente sente-se segura e tem reduzido seus medos e anseios. ${ }^{11} 0$ diálogo referido gera um ambiente harmônico, ou seja, pode ser considerado como um estímulo positivo ao mecanismo de enfrentamento materno.

As Mães 3 e 6 foram encaminhadas para cesáreas de urgência; entretanto, aparentemente, mantiveram-se calmas, por possuírem certa confiança no profissional que lhes estava prestando assistência. A gestante, durante o pré-natal e no parto, precisa sentir-se amparada, segura, para que não ocorra a exacerbação dos seus medos e anseios. ${ }^{4} \mathrm{~A}$ confiança entre a parturiente e os profissionais é capaz de gerar o sentimento de segurança. ${ }^{7}$ Sentir-se cuidada no trabalho de parto e parto pode fazer com a mulher/mãe tenha a sensação de que seu filho será bem cuidado, a confiança torna-se um elo na relação que ela cria com a equipe de saúde, e esse elo tem o poder de minimizar os seus temores quando seu filho sofre uma asfixia perinatal grave. A mulher/mãe, no momento dessa intercorrência, necessita acreditar/confiar na assistência recebida por ela e por seu filho.

\section{Aspectos negativos durante a assistência ao trabalho de parto e parto}

Ao sentir-se segura, a mulher tem reduzidos suas ansiedades e temores. Entretanto, os depoimentos de algumas mães demonstraram uma "quebra" do sentimento de segurança/ confiança entre a parturiente e os profissionais da saúde. A Mãe 5 expressa, na fala que segue, que ela se deparou em momentos distintos com aspectos positivos e negativos durante o processo, emergindo a questão do preparo e do despreparo de alguns profissionais para assistir a mulher nesse momento delicado.

O médico (nome do hospital) se apavorou porque ele ia nascer e eu estava com a pressão muito alta, e eu estava com sangramento, eu tive hemorragia. Aí ele pegou e fez os exames, ultrassom, tudo direitinho. Ele chegou e falou: "tu vai ganhar o teu nenê hoje". E eu falei ah, não está na hora. E ele, "é, mais, vai dizer isso pra ele". Só que a gente vai ter que te encaminhar para (nome do hospital) porque a gente não tem a preparação pra ele, entendesse? A gente não tem a mesma, como se diz, tecnologia da (nome do hospital), então a gente vai ter que te encaminhar pra lá. Ah, mas eu não queria ir pra lá, eu falei pra ele. É mas tu vai ter 
de ir. Aí veio uma moça, enfermeira, e me explicou tudo, o porquê. Aí, me mandaram pra lá [...] Fiquei um monte de tempo ali (nome do hospital); ela veio fazer exame de toque de novo e eu falei assim, ah moça vai nascer, eu falei pra ela. E ela, não vai nada a gente vai te dar uma injeçãozinha pra segurar. Eu, mas vai nascer, e ela, não vai nascer nada, e botou a mão na minha barriga, e o guri saiu. Ela se apavorou, ela gritava pra todo mundo porque eu ganhei ali, naquela mesa. Ela gritava todo mundo, porque foi demais. 0 o médico se apavorou e chamava a outra médica porque eu tava com hemorragia muito grande e não conseguia pararo sangue. E aí eu já comecei a me apavorar, né? Ele falava, te deita guriazinha, e eu me sentava, e eu perguntava: tá tudo bem com o nenê? E ele, te deita (Mãe 5).

A fala acima demonstra que a Mãe 5 sentiu-se "desprotegida, insegura", ao receber a notícia de que seu filho nasceria antes do tempo, e que ela teria de ser transferida para outro hospital, mudando o parto que havia planejado. Quando o nascimento da criança ocorre num período inesperado, neste caso, antecipado, os pais têm agravados os seus medos e angústias. ${ }^{12}$ No entanto, ela refere, também, que a enfermeira veio conversar com ela, e esse diálogo conseguiu tranquilizála. A interação entre a enfermeira e a Mãe 5 foi mediada por uma relação de cuidado, o diálogo não foi uma ação isolada de passagem da informação, ele foi um ato de cuidar, pois por meio dele essa mãe foi acalmada, reduzindo parte do estresse a que estava sendo exposta.

A comunicação deve ser considerada uma competência interpessoal a ser adquirida pelo profissional de saúde e que permite 0 atendimento do cliente em todas as suas dimensões. ${ }^{7}$

Embora esse diálogo tenha permitido a redução de sua ansiedade quando a criança nasceu, o profissional não estava preparado para realizar o parto, apresentando uma postura de "perda de controle", começando a "gritar", deixou-a "apavorada", insegura, com medo. 0 indivíduo que deveria passar segurança, confiança para a parturiente, com sua conduta aguçou seus medos e anseios. Refletir sobre esse fato faz reiterar a importância do preparo do profissional que presta a assistência à gestante/parturiente. É de fundamental importância que os profissionais de saúde, indiferentemente do cargo que ocupam, tenham habilidade, competência técnica e controle emocional para prestar a assistência.

A mulher deve sentir-se acolhida por profissionais competentes e "humanos". Parece uma redundância linguística dizer "profissionais humanos"; entretanto, encontrou-se na pesquisa, assim como fora encontrado anteriormente em outras pesquisas ${ }^{7,13}$, posturas e condutas realizadas por profissionais que são caracterizadas como desumanas.
A Mãe 4 descreve, a seguir, a sua percepção de ter vivenciado um descuidado.

[...] eu paguei o parto particular. [...], e eu fui bem mal tratada no hospital, eles foram rudes, grosseiros, comigo, não me passaram pra aquela mesa, aquela mesa onde a mulher fica esperando. Eu tive de ficar só na mesa de exame o tempo todo [...], fiquei ali na mesa de exame sangrando, [...] e aí quando o médico chegou ele me passou e estourou a minha bolsa e disse que o líquido estava escuro, porque eu não vi; aífoi tudo rápido, me botaram soro, pra dilatação, e ela também estava, o colo estava alto e ele tirou ela com fórceps, e ela tem até hoje a marca aqui[...] ]eu me senti muito mal, até porque eu fiz um curso (técnico em enfermagem), e eu sempre pensei, Deus que me perdoe, no dia que eu ganhar um filho eu não quero ter pelo SUS, porque durante o curso eu vi muita gente sendo mal tratada, [...] , vi um monte de gente falando absurdos, e eu pensava Deus que me perdoe, se um dia eu precisa disso, Deus o livre. Eu disse não, quando eu tiver o meu filho, eu vou pagar tudo particular, eu faço qualquer coisa, mas não tem como ter um filho pelo SUS. A enfermeira ou a médica me disse: quando tu tiver (sentindo as dores do parto) tu tem que ligar pro teu médico, a gente não tem que estar ligando, ela foi muito estúpida, grossa parecia que eles estavam me fazendo um favor, e também mal olhavam pra minha cara, só passavam reto, e eu ali sentada, esperando, sem saber de nada, eu não sei, parece que atendem a gente como se fosse lixo, ou um animal, parece que para eles estar atendendo ali no parto é um sacrifício, então, por que estão trabalhando (Mãe 4).

Com o depoimento da Mãe 4, talvez, seria possível pensar que essa mãe estivesse utilizando um mecanismo de defesa, pelo que aconteceu com sua filha, ou pelo parto, que não ocorreu como ela havia idealizado. Diante do inesperado, há mulheres que não apenas se sentem frustradas, como também fracassadas, como se tivessem falhado, ou feito tudo errado. ${ }^{1}$ Entretanto, um ser humano, sentir-se tratado como um "lixo, ou um animal" fere drasticamente o direito a igualdade, o direito a ser atendido com respeito e dignidade; além disso, fere a sua existência como ser humano.

Os sentimentos expressos pela Mãe 4 demonstram uma triste contradição, entre o que vem sendo preconizado e a realidade que ela teve de vivenciar. A humanização da assistência ao parto implica, principalmente, uma atuação profissional que respeite os aspectos biopsicossocioespirituais da mulher, oferecendo a ela e à sua família suporte emocional. ${ }^{14}$ Cuidar durante o trabalho de parto é dar atenção ao estado 
emocional da parturiente, valorizar as suas relações interpessoais, além de permitir o seu confor to e bem-estar. ${ }^{15}$

Situação semelhante à vivenciada pela Mãe 4 foi encontrada em outra pesquisa ${ }^{16}$, quando concluiu que as mulheres não estavam satisfeitas com o atendimento durante o parto, ou na sua decorrente internação, principalmente porque consideravam que alguns profissionais não tratavam bem as parturientes, sendo mal-educados e com fala grosseira, além de não levarem em consideração as colocações feitas por elas, desconsiderando-a como sujeito. A Mãe 4 foi tratada como um objeto, sendo-lhe vetado até mesmo seus direitos como ser humano.

A Mãe 4 coloca que "parece que para eles estar atendendo ali no parto é um sacrifício, então porque estão trabalhando?'. 0 questionamento da Mãe 4 foi abordado em um estudo realizado anteriormente, no qual os pesquisadores constataram em seus resultados que, para alguns profissionais, o trabalho contínuo na assistência ao pré-parto e parto é considerado muito difícil, visto que o modelo de atenção vigente não oferece suporte emocional, medicalizando em excesso a assistência ao parto. ${ }^{14}$ Essa situação, resultante desse modelo tecnicista que prima pela racionalidade e pela ausência da humanização da assistência, vem refletindo ou talvez seja o reflexo das formas de pensar e agir de cada profissional. ${ }^{15}$

Seguir esse paradigma leva a uma preocupação apenas técnica, ou seja, preocupam-se mais com a gravidez do que com a "mulher grávida", ${ }^{17}$ assim, a técnica do parto é supervalorizada e a mulher/parturiente deixa de ser vista como um ser humano biopsicossocioespiritual. A técnica/procedimento passa a ser mais valorizado do que aquele ser humano que está buscando o cuidado. Tem-se uma desvalorização da relação intersubjetiva que ali se passa.

Para contrapor-se a essa prática intervencionista, vêmse buscando a proposta da humanização da assistência ao parto, que vai ao encontro de duas grandes demandas das mulheres e da sociedade. A primeira, a da ofer ta pelo sistema público de saúde de um serviço que não seja utilizado apenas por quem não tem qualquer outra opção, mas um serviço que devolva com qualidade às mulheres o direito de ter um parto em condições que assegurem sua segurança e a de seu bebê. A segunda, que ofereça à mulher, na vivencia deste acontecimento, a possibilidade de atuar como protagonista, fazendo com que o parto deixe de ser um evento meramente biológico, e, sim, uma experiência humana, que deve ser experimentada de acordo com suas expectativas, que podem estar demonstradas em plano de parto previamente elaborado. ${ }^{14}$

A humanização da assistência à mulher durante 0 trabalho de parto e parto só será possível se houver um envolvimento entre o profissional e a parturiente. 0 ponto básico da humanização está na comunicação, no relacionamento entre as pessoas, baseado no respeito e expresso através dos gestos de amor, do ouvir, do observar.?
Conforto, bem-estar, segurança, tranquilidade e atenção são palavras que descrevem resumidamente o cuidado/ assistência que deveria ser prestada pelo profissional da saúde à parturiente. Entretanto, vale ressaltar que, em todos os casos desse estudo, as mães ficaram sozinhas durante o parto.

Eu fiquei sozinha, o tempo inteiro, apavorada (Mãe 3).

Minha prima queria assistir ao parto, mas correram ela de lá de dentro, ela entrou, e ele (médico) correu ela, disse que não é pra ela entrar. A minha prima até estava fazendo enfermagem, e o pai dela é médico, ela não ia desmaiar ou qualquer coisa dessas (Mãe 4).

As mães foram privadas de seu direito a um acompanhante durante o seu processo de parturição. Segundo a Lei 11.108 de 7 de abril de $2005^{18}$, os serviços de saúde do Sistema Único de Saúde - SUS, da rede própria ou conveniada, são obrigados a permitir a presença, junto à parturiente, de um acompanhante durante todo o período de trabalho de parto, parto e pós-parto imediato, o qual deve ser indicado pela própria parturiente.

Vale ressaltar que o período de trabalho de parto, parto e pós-parto é um momento delicado para a mulher, e separála de seus entes queridos aumenta significativamente seus medos, incertezas e inseguranças. ${ }^{8}$ É comprovado cientificamente que a presença de um acompanhante, seja ele o companheiro, um familiar, um amigo (a), o marido ou uma outra pessoa com ou sem treinamento específico para isso, diminui o uso de mediações para o alívio da dor, assim como reduz a ansiedade da parturiente, além de diminuir os índices de depressão pós-parto e aumentar a amamentação. ${ }^{14,15} \mathrm{~A}$ presença de uma pessoa amiga, conhecida ou familiar proporciona o aumento do bem-estar físico e emocional e favorece uma boa evolução no período gravídico puerperal. ${ }^{17}$

Impedir a presença de um acompanhante durante 0 trabalho de parto e parto viola o direito da mulher como cidadã brasileira. Além disso, viola sua própria capacidade de autonomia, de escolha, de optar pela presença ou não de um acompanhante, de escolher a pessoa que ela deseja que esteja ao seu lado nesse momento.

\section{CONSIDERAÇÕES FINAIS}

A partir das vivências maternas sobre a assistência recebida durante o trabalho de parto e parto, processo de parturição, em que o filho sofreu asfixia perinatal grave, foi possível perceber alguns aspectos positivos, como o diálogo, a confiança, a agilidade no atendimento, mas por outro lado, os aspectos negativos encontrados contrapõem-se aos positivos. As mulheres, sujeitos da pesquisa, ao serem expostas à situações desumanas, foram violadas nos seus direitos: direito 
a um acompanhante, direito a igualdade, a dignidade, direito de assistência às suas necessidades e ao respeito como seres humanos.

Os dados evidenciam a necessidade de se rever a assistência prestada à mulher durante o processo de parturição. As ações devem centrar-se nas necessidades do ser mulher gestante e não em um objeto em que será realizado um procedimento. Humanizar a assistência implica modificar a cultura assistencial tecnicista que se encontra impregnada, por vezes até inconscientemente nos indivíduos que prestam o cuidado. Essa conduta faz com que o profissional se preocupe mais com a eficiência no ato a ser realizado do que envolver-se com o ser humano no qual está desenvolvendo a ação.

Esse estudo encontra-se distante do esgotamento da questão e, portanto, enfatiza-se a necessidade de prosseguir nas pesquisas que abordam a temática do cuidado prestado à mulher durante o trabalho de par to e parto, principalmente no que concerne à assistência prestada a essa parturiente quando ocorre uma intercorrência clínica durante o processo.

\section{REFERÊNCIAS}

1. Maldonado MT. Psicologia da gravidez parto e puerpério. $15^{\mathrm{a} e d}$. São Paulo(SP): Saraiva; 2000.

2. Soares DC. Vivenciando o ser prematuro extremo e sua família no contexto hospitalar e domiciliar. [dissertação de mestrado] Rio Grande (RS): Universidade Federal do Rio Grande; 2006

3. Iserhard ACM, Budó MLD, Neves ET, et al. Práticas culturais de cuidados de mulheres mães de recém-nascidos de risco do sul do Brasil. Esc Ana Nery Rev Enferm 2009; 13(1): 116-22.

4. Guimarães GP, Monticelli M. A formação do apego psia/recém-nascido pré-termo e/ou de baixo peso no método Mãe Canguru: uma contribuição da enfermagem. Texto\& Contexto Enferm 2007; 16(4): 626-35.

5. Aguiar RMLP. Sofrimento fetal agudo. In: Benzercry R, organizador. Tratado de Obstetrícia-FEBRASGO. Rio de Janeiro (RJ): Revinter; 2001. p.335- 42 .

6. Milbrath MM. Cuidado da família à criança portadora de paralisia cerebral nos três primeiros anos de vida 2008. [dissertação de mestrado]. Rio Grande(RS): Escola de Enfermagem, Fundação Universidade Federal de Rio Grande; 2008. 188 f

7. Wolff LR, Waldow VR. Violência consentida: mulheres em trabalho de parto e parto. Saude Soc 2008; 17(3): 138-51.

8. Ministério da Saúde (Brasil). Pré-natal e puerpério: atenção qualificada e humanizada. Manual técnico. Brasília (DF); 2005. 158p.

9 .Fortes PAC. Ética, direitos dos usuários e políticas de humanização da atenção à saúde. Saude Soc 2004; 13(3): 30-35.

10.Minayo MC. 0 desafio do conhecimento: pesquisa qualitativa em saúde. 10ª ed. São Paulo (SP): Hucitec; 2007.
Milbrath VM, Amestoy SC, Soares DC, Siqueira HCH

11. Ministério da Saúde (BR). Secretaria de Políticas da Saúde. Área Técnica de Saúde da Mulher. Parto, aborto e puerpério: assistência humanizada à mulher. Brasília (DF);2001 .

12. Rabelo MZS, Chaves EMC, Cardoso MVLML, et al. Sentimentos e expectativas das mães na alta hospitalar do recém-nascido prematuro. Acta Paul Enferm 2007; 20(3): 333-37.

13. Gomes AMA, Nations MK, Luz MT. Pisada como pano de chão: experiência de violência hospitalar no nordeste Brasileiro. Saude Soc 2008; 17(1):61-72.

14.Dias MAB, Domingues RMS. Desafios na implantação de uma política humanizada da assistência hospitalar ao parto. Cienc Saude Colet 2005; 10(3): 669-705.

15.Carraro TE, Knobel R, Radünz V, et al. Cuidado e conforto durante o trabalho de parto e parto: na busca pela opinião das mulheres. Texto\&Contexto Enferm 2006; 15(n esp): 97-104.

16.Queiroz MVO, Jorge MSB, Marques JF,Cavalcante AM,Moreira KAP. Indicadores da qualidade da assistência ao nascimento baseadona satisfação de puéperas. Texto e Contexto Enferm 2007;16(3):479-87.

17.Bruggemann OM, Osis MJD, Parpinelli MA. Apoio no nascimento: percepções de profissionais e acompanhantes escolhidos pela mulher. Rev Saude Publica 2007, 41(1): 44-52.

18.Lei $\mathrm{n}^{0} 11.108$, de 7 de abril de 2005. Dispõe sobre o subsistema de acompanhamento durante o trabalho de parto, parto e pós-parto imediato. Diário Oficial da República Federativa do Brasil, Brasília (DF), 8 abr 2005. Disponível em: http://www.planalto.gov.br/ccivil_03/_Ato20042006/2005/Lei/L11108.htm

${ }^{1}$ Artigo extraído da Dissertação: Cuidado da família à criança portadora de paralisia cerebral nos três primeiros anos de vida, apresentada ao Programa de Pós-Graduação em Enfermagem da Universidade Federal do Rio Grande.

\section{NOTA}

aArtigo extraído da Dissertação: Cuidado da família à criança portadora de paralisia cerebral nos três primeiros anos de vida, apresentada ao Programa de Pós-Graduação em Enfermagem da Universidade Federal do Rio Grande. 